\title{
SYNCHRONIZATION OF OESTRUS IN HEIFERS USING INTRA-VAGINAL PESSARIES IMPREGNATED WITH SC-9880 AND PMSG
}

\author{
D. F. WISHART AND B. D. HOSKIN \\ G. D. Searle and Company, High Wycombe, Bucks. \\ (Received 3rd November 1967, revised 27th Fanuary 1968)
}

\begin{abstract}
Summary. Heifers were treated with intra-vaginal pessaries impregnated with $200 \mathrm{mg}$ SC-9880 (17 $\alpha$-acetoxy- $9 \alpha$-fluoro $11 \beta$-hydroxy-4pregnene-3,20 dione). One or 2 days before removal of the pessaries (21 days after insertion) each heifer received a single intra-muscular injection of 750 i.u. PMSG.

Of the eighty-one treated heifers, sixty-six retained the pessaries for the prescribed period; fifty-five of these $(83.3 \%)$ showed oestrus 24 to 72 $\mathrm{hr}$ after removal of the pessary. Of fifty-five heifers served or inseminated, twenty-four $(43.7 \%)$ conceived. Of thirty-three heifers served at the second oestrous period, twenty-one $(61.9 \%)$ conceived.
\end{abstract}

\section{INTRODUCTION}

Robinson (1965) first reported the successful use of intra-vaginal pessaries (Syncro-Mate, G. D. Searle \& Co) impregnated with SC-9880 (Gronolone, G. D. Searle \& Co.) for the synchronization of oestrus in the cyclical Merino ewe. He suggested that this technique might offer an effective method of controlling the time of oestrus and ovulation in other farm animals. So far, only three reports have been published concerning the use of the intra-vaginal approach of chronic progestin therapy to adult cattle. Mauléon \& Rey (1966) used pessaries impregnated with $120 \mathrm{mg}$ SG-9880. Shimizu, Toyoda, Takeuchi, Kawai \& Adachi (1967) have reported the use of pessaries impregnated with $100 \mathrm{mg}$ and $200 \mathrm{mg}$ SC-9880 for oestrous synchronization in adult Japanese black cattle. Recently, Carrick \& Shelton (1967) have reported the use of pessaries impregnated with $100 \mathrm{mg}$ and $200 \mathrm{mg}$ SC-9880. This paper deals with the results of treatment of three small groups of 15- to 18-month heifers with pessaries impregnated with $200 \mathrm{mg}$ SC-9880: each heifer received 750 i.u. PMSG (Gestyl, Organon Laboratories Ltd) before removal of the pessary.

\section{MATERIALS AND METHODS}

A total of 108 heifers, aged from 15 to 18 months, were presented for treatment from February to April 1967. The heifers were housed in yards on three different farms (Trial I, Trial II and Trial III) and were in varying degrees of 
body condition. Throughout the investigation animals received concentrate feeding in the form of grain or silage twice daily. Hay and water were freely available. There were sixteen Friesians (Trial I), thirty-five cross-bred Herefords (Trial II) and fifty-seven heifers of varying breeds (Trial III).

Using a vaginal speculum, the Cronolone pessaries were expelled from a plastic tube and deposited close to the cervical os. Each pessary, consisting of two discs held together by a terylene cord, was impregnated with $200 \mathrm{mg}$ SC-9880. The cord was used to withdraw the pessary 21 days after insertion. Heifers which retained the pessaries for the prescribed period received a single intra-muscular injection of 750 i.u. PMSG (Gestyl, Organon Laboratories Ltd) either the day before (Trials II and III) or 2 days before (Trial I) the removal of the pessaries.

Oestrus was detected either by trial with a bull (Trial I) or by behaviour towards other heifers and inspection for physical signs of oestrus.

In Trial I, animals were inspected for signs of oestrus every $2 \mathrm{hr}$ after removal of pessaries between 08.00 hours and midnight. A further observation was made at 04.00 hours. After the end of oestrus, rectal examinations were made every $2 \mathrm{hr}$ to determine the time of ovulation. In Trials II and III the heifers were inspected for signs of oestrus four times a day.

All heifers were inseminated artificially except for a few heifers in Trial I which were served by the bull used for detection of oestrus. All animals were examined for pregnancy by rectal palpation 8 weeks after insemination or service; conception rate, here, means the percentage of animals diagnosed pregnant at this examination.

\section{RESULTS}

Of the 108 heifers presented for treatment, twenty-seven were discarded because of an existing pregnancy or because of genital abnormalities. Of the remaining eighty-one, fifteen failed to retain the pessaries for 21 days; most of these were lost within the first $48 \mathrm{hr}$ after treatment.

A total of fifty-five out of sixty-six heifers $(83.3 \%)$ retaining pessaries, exhibited oestrus 25 to $72 \mathrm{hr}$ after the end of treatment. The distribution of the time of onset of oestrus following pessary removal is summarized in Table 1 . No heifers were observed in oestrus during the period 0 to $24 \mathrm{hr}$ following the end of treatment. In the period 25 to $36 \mathrm{hr}$ post-treatment, twenty-six heifers were observed in oestrus, a further twenty-one heifers were in oestrus in the period 37 to $48 \mathrm{hr}$, a further five heifers in the period 49 to $60 \mathrm{hr}$ and three in the period 61 to $72 \mathrm{hr}$. Of the thirty-nine heifers examined rectally at the time of pessary removal, twenty-nine $(74.3 \%$ ) had palpable follicles in one ovary. There was no evidence of multiple follicle formation following the use of 750 i.u. PMSG.

In Trial I the average duration of oestrus for eight heifers was $13 \mathrm{hr}$ (S.E. $0 \cdot 67)$. In this trial the average time to the onset of oestrus after pessary removal was $35 \mathrm{hr}$ (S.E. 0.76). The average interval from the end of oestrus to the time of ovulation, as determined by rectal palpation in seven heifers, was $11 \mathrm{hr}$ (S.E. 0.63). 
The duration of di-oestrus in heifers failing to conceive at the first oestrous cycle ranged from 18 to 27 days (Table 2).

Thus, oestrus was effectively synchronized in fifty-five heifers within $72 \mathrm{hr}$ after the end of treatment, but heifers failing to conceive at this oestrus exhibited a recurrence of oestrus over a period of 12 days.

In the three trials, eleven heifers failed to exhibit behavioural oestrus during the first 7 days after pessary withdrawal. Five of these showed physical signs of oestrus (vulval swelling, increased mucus secretion, etc.). All were examined

TABLE 1

THE DISTRIBUTION OF TIME OF ONSET OF HEAT FOLLOWING END OF TREATMENT

\begin{tabular}{c|c|c|c|c}
\hline $\begin{array}{c}\text { Onset (hr } \\
\text { after removal } \\
\text { of pessary) }\end{array}$ & Trial I & Trial II & Trial III & All \\
\hline 25 to 36 & 5 & 11 & 10 & 26 \\
37 to 48 & 1 & 15 & 5 & 21 \\
49 to 60 & 2 & 0 & 3 & 5 \\
61 to 72 & 0 & 0 & 3 & 3 \\
Total & & & & 55 \\
\hline
\end{tabular}

TABLE 2

THE DURATION OF DI-OESTRUS IN HEIFERS FOLLOWING TREATMENT

\begin{tabular}{l|cccccccccc}
\hline $\begin{array}{l}\text { Duration of } \\
\text { di-oestrus (days) }\end{array}$ & 18 & 19 & 20 & 21 & 22 & 23 & 24 & 25 & 26 & 27 \\
\hline No. of heifers & 2 & 3 & 2 & 5 & 4 & 5 & 2 & 0 & 0 & 3 \\
\hline
\end{tabular}

TABLE 3

DAY OF REGURRENCE OF OESTRUS FOLLOWING WITHDRAWAL OF PESSARY

\begin{tabular}{l|cccccccccccc}
\hline Day* & 17 & 18 & 19 & 20 & 21 & 22 & 23 & 24 & 25 & 26 & 27 & 28 \\
\hline No. of heifers & 1 & 0 & 4 & 3 & 6 & 3 & 4 & 6 & 3 & 0 & 0 & 3 \\
\hline
\end{tabular}

* Day of withdrawal of pessary = Day 0 .

per rectum 14 days after removal of the pessaries and the five heifers which had exhibited the external signs of oestrus each had a palpable corpus luteum in one ovary. In Trial I, two heifers showed no evidence of ovarian activity as judged by the presence or absence of a palpable corpus luteum on Day 14. Of the eleven heifers, seven exhibited oestrus between Days 17 and 28 after treatment. Within a 30-day period following the end of treatment, sixty-two out of sixty-six heifers had exhibited oestrus. 
In Trial I some of the heifers were served naturally at the first oestrous cycle by the bull used for detection of oestrus. The remainder of the heifers were inseminated artificially. All heifers in Trials II and III were artificially inseminated. Of the fifty-five heifers served or artificially inseminated at the first oestrus, twenty-four conceived (43.7\%, see Table 4$)$. A total of thirtythree heifers was inseminated between Days 17 and 28 (second oestrous cycle), of which twenty-one $(61.9 \%)$ conceived. During 30 days following the end of treatment sixty-two out of sixty-six heifers $(93.9 \%)$ were observed in oestrus and forty-five of the sixty-two heifers $(72.6 \%)$ served or inseminated conceived. In all three trials the conception rate at the second post-treatment oestrus was higher than at the first oestrous period. Statistically, the effect of first versus second cycle mating on conception rate is non-significant $\left(\chi^{2}=3 \cdot 34\right.$; d.f. $\left.=1\right)$.

TABLE 4

NUMBERS OF HEIFERS SHOWING OESTRUS AND THE NUMBERS CONCEIVING AT THE FIRST AND SECOND OESTROUS PERIODS AFTER TREATMENT

\begin{tabular}{c|c|c|c|c|c|c|c}
\hline \multirow{2}{*}{ Trial } & $\begin{array}{c}\text { No. } \\
\text { retaining } \\
\text { pessary }\end{array}$ & \multicolumn{2}{|c|}{ First oestrus } & \multicolumn{2}{|c|}{ Second oestrus } & \multicolumn{2}{|c}{ Total } \\
\cline { 3 - 6 } \cline { 5 - 7 } & Oestrus & Conceived & Oestrus & Conceived & Oestrus & Conceived \\
\hline I & 12 & 8 & 2 & 8 & 6 & 12 & 8 \\
II & 27 & 26 & 9 & 15 & 9 & 27 & 18 \\
III & 27 & 21 & 13 & 10 & 6 & 23 & 19 \\
Total & 66 & 55 & 24 & 33 & 21 & 62 & 45 \\
\hline
\end{tabular}

\section{DISCUSSION}

The results indicate that the use of $200 \mathrm{mg}$ SC-9880-impregnated pessaries followed by an injection of 750 i.u. PMSG before removal of the pessary is a highly effective method for the synchronization of oestrus in heifers.

Mauléon \& Rey (1966) reported that the use of sponges impregnated with $120 \mathrm{mg}$ SG-9880 resulted in a higher number of double ovulations than normal in this species. There was no evidence in this study of multiple follicle formation.

Unsatisfactory pessary retention, which was observed by Shimizu et al. (1967) and Carrick \& Shelton (1967), was also met in these trials. Modifications to the shape and size of the pessary or to the type of material used may overcome the problem.

The treatment of larger groups of animals may show that fertility at the first post-treatment oestrus is significantly lower than at the first cycle. From the results in this paper the difference in fertility between the first and the second cycles did not attain significance.

From this small study it may be concluded that the time relationships of oestrus and ovulation are normal in heifers treated with $200 \mathrm{mg}$ SG-9880impregnated pessaries and with $750 \mathrm{i}$.u. PMSG injected intra-muscularly during the 48-hr period before removal of the pessary. Oestrus and ovulation were successfully inhibited in 15- to 18-month-old heifers of the breeds studied. The 
dose of PMSG given did not have a superovulatory effect. The fact that follicles were palpable at the time of removal of the pessary may be due to the injection of PMSG before removal or to the failure of SC-9880 to inhibit FSH secretion.

The apparent lowering of fertility at the first post-treatment cycle supports the findings of other workers using various progestins. The reason for any lowered fertility must be determined before oestrous synchronization in the bovine by means of progestins can become a practical proposition.

\section{REFERENGES}

Carrick, M. J. \& Shelton, J. N. (1967) The synchronization of oestrus in cattle with progestagenimpregnated intravaginal sponges. F. Reprod. Fert. 14, 21.

MAulÉon, P. \& ReY, J. (1966) Effects of fluorogestone acetate absorbed by the vaginal route on oestrus and ovulation in cattle. Ind int. Congr. on Hormonal Steroids, Milan. Excerpta Med. Int. Congr. Series No. 111, p. 348.

Robinson, T. J. (1965) Use of progestagen impregnated sponges inserted intra-vaginally or subcutaneously for the control of the oestrus cycle in the sheep. Nature, Lond. 206, 39.

Shimizu, H., Toyoda, Y., Takeuchi, S., Kawai, T. \& Adachi, S. (1967) Synchronization of oestrus and subsequent fertility of beef cattle following the intravaginal administration of gestagen. 7. Reprod. Fert. 13, 555. 